\title{
Transfer of Bacteroides splanchnicus to Odoribacter gen. nov. as Odoribacter splanchnicus comb. nov., and description of Odoribacter denticanis sp. nov., isolated from the crevicular spaces of canine periodontitis patients
}

\author{
John M. Hardham, ${ }^{1}$ Kendall W. King, ${ }^{1}$ Kimberly Dreier, ${ }^{1}$ Jason Wong, ${ }^{1}$ \\ Catherine Strietzel, ${ }^{1}$ Rob R. Eversole, ${ }^{2}$ Cornelia Sfintescu ${ }^{3}$ \\ and Richard T. Evans ${ }^{3}$ \\ ${ }^{1}$ Pfizer Inc., Veterinary Medicine Research and Development, 7000 Portage Road, Kalamazoo, \\ MI 49001, USA \\ ${ }^{2}$ Western Michigan University, Department of Biological Sciences, 3441 Wood Hall, Kalamazoo, \\ MI 49008, USA \\ ${ }^{3}$ University at Buffalo, School of Dental Medicine, Department of Oral Biology, 219 Foster Hall, \\ Buffalo, NY 14214, USA
}

Correspondence

John M. Hardham

john.m.hardham@pfizer.com

\begin{abstract}
Numerous novel anaerobic bacteria were isolated from the crevicular spaces of dogs with periodontitis. The phenotypic characteristics of these bacterial isolates indicated that they were similar to members of the genus Porphyromonas. However, comparison of the 16S rRNA gene sequences of the isolates indicated that they were related to members of the Bacteroides splanchnicus subgroup. A representative of the novel isolates, strain $\mathrm{B}_{106}{ }^{\top}$, induced alveolar bone loss in a mouse model of experimental periodontal disease. Based on biochemical, morphological, molecular phylogenetic, and pathogenic evidence, it is proposed that the taxonomic subgroup containing these novel isolates and $B$. splanchnicus should be classified in a new genus, Odoribacter gen. nov., within the family 'Porphyromonadaceae'. In addition, it is proposed that $B$. splanchnicus should be reclassified as Odoribacter splanchnicus comb. nov., and that the newly identified isolates should be classified as representing Odoribacter denticanis sp. nov., the type strain of which is $\mathrm{B} 106^{\top}$ (=ATCC PTA $-3625^{\top}=\mathrm{CNCM} \mathrm{I}^{\mathrm{T}} 3225^{\mathrm{T}}$ ).
\end{abstract}

The taxonomy of the phylum Bacteroidetes has undergone considerable changes within the last decade. The advent of 16S rRNA gene-DNA sequence analysis has vastly improved the ability of scientists to genetically place a bacterium into an appropriate genus. Members of the families Bacteroidaceae, 'Porphyromonadaceae' and 'Prevotellaceae' have been found to play important roles in oral disease as well as in other anaerobic infections of

Abbreviations: $\mathrm{ABC}$, alveolar bone crest; $\mathrm{ANI}$, anaerobe identification; CEJ, cemento-enamel junction.

The GenBank/EMBL/DDBJ accession numbers for the 16S rRNA gene sequences of Odoribacter denticanis strains $\mathrm{B} \mathrm{C6}^{\top}, \mathrm{B} 107, \mathrm{~B} 113, \mathrm{~B} 126$, B129, B135, B140, B150, B151, B152, B155, B163, B171, B172, $\mathrm{B} 174, \mathrm{~B} 183$ and B264 are AY560020, AY560021, AY560022, AY560023, AY560024, AY560025, AY560026, AY560027, AY560028, AY560029, AY560030, AY560031, AY560032, AY560033, AY560034, AY560035 and AY560036, respectively. The GenBank/EMBL/DDBJ accession number for the fimA gene of strain $\mathrm{B} 106^{\top}$ is $\mathrm{AY} 573801$. humans and companion animals (Haffajee \& Socransky, 1994). Historically, the genera Porphyromonas and Bacteroides have been greatly intertwined, due, in part, to the original classification of many Porphyromonas isolates as belonging to the genus Bacteroides (Shah \& Collins, 1988). Porphyromonas species and Bacteroides species both generally appear pigmented on blood agar after extended incubation. Members of these two genera are Gramnegative, non-spore-forming, non-motile rods (Holt et al., 1994). At the time of writing, the genera Porphyromonas and Bacteroides comprised approximately 16 and 77 recognized species, respectively (List of Prokaryotic names with Standing in Nomenclature; http://www.bacterio. cict.fr).

We previously conducted an extensive field study that resulted in the collection of a large number of gingival crevicular fluid samples from companion animals with periodontitis. Analysis of these samples permitted the types and frequencies of pigmented anaerobic bacteria present in 
diseased crevicular spaces to be determined (Hardham et al., 2003, 2005a). Briefly, paper-point samples were taken from the crevicular spaces of dogs and cats with periodontitis. Samples were only taken from teeth with pocket depths of greater than $2 \mathrm{~mm}$ (cats) or $3 \mathrm{~mm}$ (dogs). The samples were diluted, plated on Brucella blood agar (Anaerobe Systems) and incubated at $37^{\circ} \mathrm{C}$ in an anaerobic environment $\left(\begin{array}{lllll}5 \% & \mathrm{H}_{2} / 5 \% & \mathrm{CO}_{2} / 90 \% & \mathrm{~N}_{2}\end{array}\right)$. Individual, well-isolated colonies were restreaked on Brucella blood agar in order to obtain pure cultures. A region of the $16 \mathrm{~S}$ rRNA gene was PCR amplified directly from individual colonies using the universal primers D56 (5'-GGATTAGATACCCTGGTAGTC-3') (Rumpf et al., 1999) and D57 (5'-CCCGGGAACGTATTCACCG-3') (Slots et al., 1995) (Invitrogen). PCR fragments were purified and directly sequenced. The DNA sequences obtained were analysed for relatedness to DNA sequences in the available databases at the National Center for Biotechnology Information (NCBI; http://www.ncbi.nlm. nih.gov/) using the BLASTN software (Altschul et al., 1990). Nearest matches were used to presumptively classify the bacterial genus and species. We identified numerous isolates whose $16 \mathrm{~S}$ rRNA gene sequences did not have highly similar matches in the available databases, indicating that they may represent novel isolates. One group of these isolates (Table 1) appeared to represent a novel species originally referred to as 'Porphyromonas denticanis' (Hardham et al., 2003, 2005a, b). Herein, we propose that this novel species should be placed into a new genus with the name Odoribacter gen. nov.

\section{Biochemical analysis}

Strain $\mathrm{B} 106^{\mathrm{T}}$ was isolated from an adult, mixed-breed, male dog of unknown age with periodontal disease. A

Table 1. Canine clinical bacterial isolates of $O$. denticanis used in this study

\begin{tabular}{|llc|}
\hline Strain & \multicolumn{1}{c|}{ Tooth } & Pocket depth $(\mathbf{m m})$ \\
\hline B106 $^{\text {T }}$ & Lower left first molar & 4 \\
B107 & Lower left first molar & 4 \\
B113 & Upper left pre molar no. 4 & 4 \\
B126 & Upper right first molar & 4 \\
B129 & Upper right first molar & 4 \\
B135 & Upper left pre molar no. 3 & 4 \\
B140 & Lower left first molar & 4 \\
B150 & Lower left first molar & 4 \\
B151 & Lower left first molar & 4 \\
B152 & Lower left first molar & 4 \\
B155 & Lower left first molar & 4 \\
B163 & Upper left pre molar no. 4 & 4 \\
B171 & Lower left pre molar no. 4 & 7 \\
B172 & Lower left pre molar no. 4 & 7 \\
B174 & Lower left pre molar no. 4 & 6 \\
B183 & Lower left pre molar no. 4 & 3 \\
& & \\
\hline
\end{tabular}

paper-point sample was obtained from the mandibular first molar that had a periodontal pocket of $4 \mathrm{~mm}$ in depth and a gingival index of 1 (Harvey, 1998). The sample was processed as described above. The purified cells were subjected to biochemical analysis using a RapID ANA II clinical test kit (Remel) and the Vitek Anaerobe Identification (ANI) card system (bioMérieux). Briefly, confluent bacterial cells on Brucella blood agar plates were resuspended to McFarland no. 3 equivalency. The suspension was added to the RapID ANA II test wells or the Vitek ANI card and incubated for $4 \mathrm{~h}$ at $37{ }^{\circ} \mathrm{C}$. At the end of the incubation period, the results of the biochemical tests were recorded.

Table 2 shows the results of RapID ANA II testing for strain $B 106^{\mathrm{T}}$ as well as for six related bacteria. Of the 18 tests performed by using the RapID ANA II kit, only two (leucyl-glycine and indole) were positive for strain $\mathrm{B} 106^{\mathrm{T}}$. In comparison, Porphyromonas gingivalis ATCC $33277^{\mathrm{T}}$, Prevotella intermedia ATCC $25611^{\mathrm{T}}$, Tannerella forsythensis ATCC $43037^{\mathrm{T}}$, Bacteroides thetaiotaomicron ATCC $29148^{\mathrm{T}}$, Bacteroides fragilis ATCC $25285^{\mathrm{T}}$ and Bacteroides splanchnicus ATCC $29572^{\mathrm{T}}$ yielded 5, 5, 10, 9 (plus 1 variable), 11 and 7 (plus 1 variable) positive tests, respectively.

The biochemical reaction patterns of strain $\mathrm{B} 106^{\mathrm{T}}$, Porphyromonas gingivalis ATCC 53977, and Fusobacterium nucleatum subsp. nucleatum ATCC 23726 were determined using the Vitek ANI card (Table 3). Strain $\mathrm{B} 106^{\mathrm{T}}$ yielded only two positive tests (indole and triphenyl tetrazolium), whereas Porphyromonas gingivalis ATCC

Table 2. RapID ANA II biochemical tests for strain $B 106^{\top}$ (Odoribacter denticanis gen. nov., sp. nov.) and related strains

Strains: 1, B106 ${ }^{\mathrm{T}} ; 2$, Porphyromonas gingivalis ATCC $33277^{\mathrm{T}}$; 3, Prevotella intermedia ATCC $25611^{\mathrm{T}}$; 4, T. forsythensis ATCC $43037^{\mathrm{T}}$; 5, B. thetaiotaomicron ATCC $29148^{\mathrm{T}} ; 6$, B. fragilis ATCC $25285^{\mathrm{T}} ; 7, B$. splanchnicus ATCC $29572^{\mathrm{T}}$. Tests for urea, $\alpha$-arabinosidase, and hydrolysis of leucyl-glycine, glycine and proline generated the same results for the bacteria indicated. + , Positive; - , negative; $v$, variable.

\begin{tabular}{|c|c|c|c|c|c|c|c|}
\hline Biochemical test & 1 & 2 & 3 & 4 & 5 & 6 & 7 \\
\hline$\beta$-Disaccharide & - & - & - & - & - & + & - \\
\hline$\beta$-Galactosidase & - & - & - & + & + & + & - \\
\hline$\alpha$-Glucosidase & - & - & + & + & + & + & - \\
\hline$\beta$-Glucosidase & - & - & - & + & $\mathrm{V}$ & + & - \\
\hline$\alpha$-Galactosidase & - & - & - & - & + & + & + \\
\hline$\alpha$-Fucosidase & - & - & - & + & + & + & + \\
\hline$N$-Acetylglucosaminidase & - & + & - & + & + & + & + \\
\hline Alkaline phosphatase & - & + & + & + & + & + & $\mathrm{V}$ \\
\hline \multicolumn{8}{|l|}{ Hydrolysis of: } \\
\hline Phenylalanine & - & - & - & + & - & + & - \\
\hline Arginine & - & + & + & + & + & + & + \\
\hline Serine & - & - & - & + & - & - & - \\
\hline Pyrrolidonyl & - & - & - & - & - & - & + \\
\hline Indole & + & + & + & - & + & - & + \\
\hline
\end{tabular}


Table 3. Vitek ANI biochemical tests for strain $\mathrm{B} 106^{\top}$ (Odoribacter denticanis gen. nov., sp. nov.) and related strains

Strains: $1, \mathrm{~B}_{106}{ }^{\mathrm{T}} ; 2$, Porphyromonas gingivalis ATCC 53977; 3, F. nucleatum ATCC 23726. The other 25 tests in the Vitek ANI kit produced the same results for the bacteria indicated. +, Positive; -, negative.

\begin{tabular}{|lccc|}
\hline Biochemical test & $\mathbf{1}$ & $\mathbf{2}$ & $\mathbf{3}$ \\
\hline Gram & Negative & Negative & Negative \\
Alkaline phosphatase & - & + & - \\
$N$-Acetylglucosaminidase & - & + & - \\
Proteolytic cleavage of & - & + & - \\
N-benzoyl-DL-arginine & & & \\
p-nitroanilide & & & \\
Glutamyl glutamic acid arylamidase & - & - & + \\
& & & \\
\end{tabular}

53977 yielded five positive tests (indole, $p$-nitrophenyl phosphate, $p$-nitrophenyl $N$-acetyl $\beta$-D-glucosaminidase, $N$-benzoyl-DL-arginine $p$-nitroanilide and triphenyl tetrazolium). Of the 12 tests that were in common between the RapID ANA II and the Vitek ANI card, all yielded similar results. Using the database supplied by Vitek, strain $\mathrm{B} 106^{\mathrm{T}}$ was identified incorrectly as $F$. nucleatum with a confidence level of $63 \%$ (data not shown). The misidentification may be due to a lack of veterinary pigmented anaerobic bacterial isolates in the Vitek database.

\section{Phylogenetic analysis}

The 16S rRNA gene from strain B106 ${ }^{\mathrm{T}}$ was PCR amplified in triplicate using the primers D134 (5'-GAGTTTGATCCTGGCTCAGG-3') and D57 (Slots et al., 1995) (Invitrogen). The PCR products were pooled, purified and desalted, and subjected to direct DNA sequence analysis. BLASTN (Altschul et al., 1990) searches of the non-redundant nucleotide database at the NCBI using the $16 \mathrm{~S}$ rRNA gene sequence of strain $\mathrm{B} 106^{\mathrm{T}}$ indicated that strain $\mathrm{B}_{106^{\mathrm{T}}}$ was related to members of the genus Bacteroides. The $16 \mathrm{~S}$ rRNA gene sequence of strain $\mathrm{B} 106^{\mathrm{T}}$ was most closely related to the 16S rRNA gene sequence of Bacteroidetes sp. oral clone FX069 (GenBank accession number AY134906), with $96.3 \%$ identity over $1465 \mathrm{bp}$. Bacteroidetes sp. oral clone FX069 was isolated from a human patient with necrotizing ulcerative periodontitis during a study to define the bacterial species associated with necrotizing ulcerative periodontitis in HIV-positive patients (Paster et al., 1994).

Phylogenetic analysis based on 16S rRNA gene sequences was performed using CLUSTAL_X version 1.81 software (Thompson et al., 1997). Phylogenetic trees were generated using the neighbour-joining method (Saitou \& Nei, 1987). Bootstrap values were obtained using 1000 replicates. Fig. 1 shows the results of phylogenetic analysis for strain $\mathrm{B} 106^{\mathrm{T}}$. The placement of the major genera (Porphyromonas, Bacteroides, Prevotella, Tannerella, etc.) is in agreement with previously published phylogenetic trees for the phylum Bacteroidetes (Paster et al., 1994; Sakamoto et al., 2002; Shah et al., 1998).

Strain $\mathrm{B} 106^{\mathrm{T}}$ is grouped in an outgroup of Bacteroides that includes B. splanchnicus (Werner et al., 1975), several oral isolates and numerous uncultured strains. An $88.9 \%$ bootstrap confidence value at the branch point of $O$. denticanis and B. splanchnicus indicates a moderately high degree of certainty that these two organisms are related. However, historically, there has been discussion about the placement of B. splanchnicus within the genus Bacteroides (Paster et al., 1994; Shah et al., 1998). Paster et al. (1994) suggested that $B$. splanchnicus may represent a new genus. Shah et al. (1998) indicated that B. splanchnicus shares many chemotaxonomic properties with members of the genus Porphyromonas. Our data are in agreement with this hypothesis, as the $B$. splanchnicus/O. denticanis $\mathrm{B} 106^{\mathrm{T}}$ group branches closer to the genus Porphyromonas than to the genus Bacteroides (Fig. 1).

An approximately $580 \mathrm{bp}$ region of the $16 \mathrm{~S}$ rRNA gene from 15 other canine clinical isolates of $O$. denticanis (Table 1) was PCR amplified (in triplicate), using the primers D56 and D57 described above. The PCR products were purified, desalted and pooled. The DNA sequence of the PCR products was then determined. The partial $16 \mathrm{~S}$ rRNA gene sequences from the $16 \mathrm{O}$. denticanis isolates were found to all cluster together into six groups of identical sequences (I: B106 ${ }^{\mathrm{T}}$, B107, B126, B129, B135, B140, B163, B174; II: B150, B151, B152; III: B171, B183; IV: B113; V: B155; and VI: $\mathrm{B} 172)$. The largest divergence between these six groups was between groups II and VI, which showed $97 \%$ identity over the 516 bp analysed. Each of these partial $16 \mathrm{~S}$ rRNA gene sequences was found to be highly related to that of strain $\mathrm{B}^{106^{\mathrm{T}}}$ (Fig. 1). Recently, Elliot and others (unpublished sequence submission) have deposited in the NCBI nucleotide databases six partial 16S rRNA gene sequences from bacteria found in canine dental plaque that have homology to $O$. denticanis $16 \mathrm{~S}$ rRNA gene sequences. Additional sequences deposited recently by Baldwin and others (unpublished sequence submission) and Eckburg et al. (2005) from bacteria isolated from human periodontal pockets and human intestine, respectively, also have homology to the $O$. denticanis $16 \mathrm{~S}$ rRNA gene sequences. Based on these observations, all of these isolates appear to be varying strains of the same species.

In order to analyse further the relationship between strain $B 106^{\mathrm{T}}$ and the genus Porphyromonas, the fimA gene was PCR amplified (in triplicate) using the degenerate PCR primers D122 (5' -TGGCTAARYTGACYGTAATGGTYTA$\left.3^{\prime}\right)$ and D123 (5'-AGTTYACYAATACAGGRTAATAGGT$\left.3^{\prime}\right)$ (Invitrogen). The PCR products were purified, desalted and pooled, and subjected to direct DNA sequence analysis. BLASTP searches (Altschul et al., 1990) of the non-redundant polypeptide database at the NCBI using the FimA amino acid sequence indicated that the FimA protein of strain $B 106^{\mathrm{T}}$ was related to the FimA protein from members of the genus Porphyromonas. Fig. 2 shows the phylogenetic 


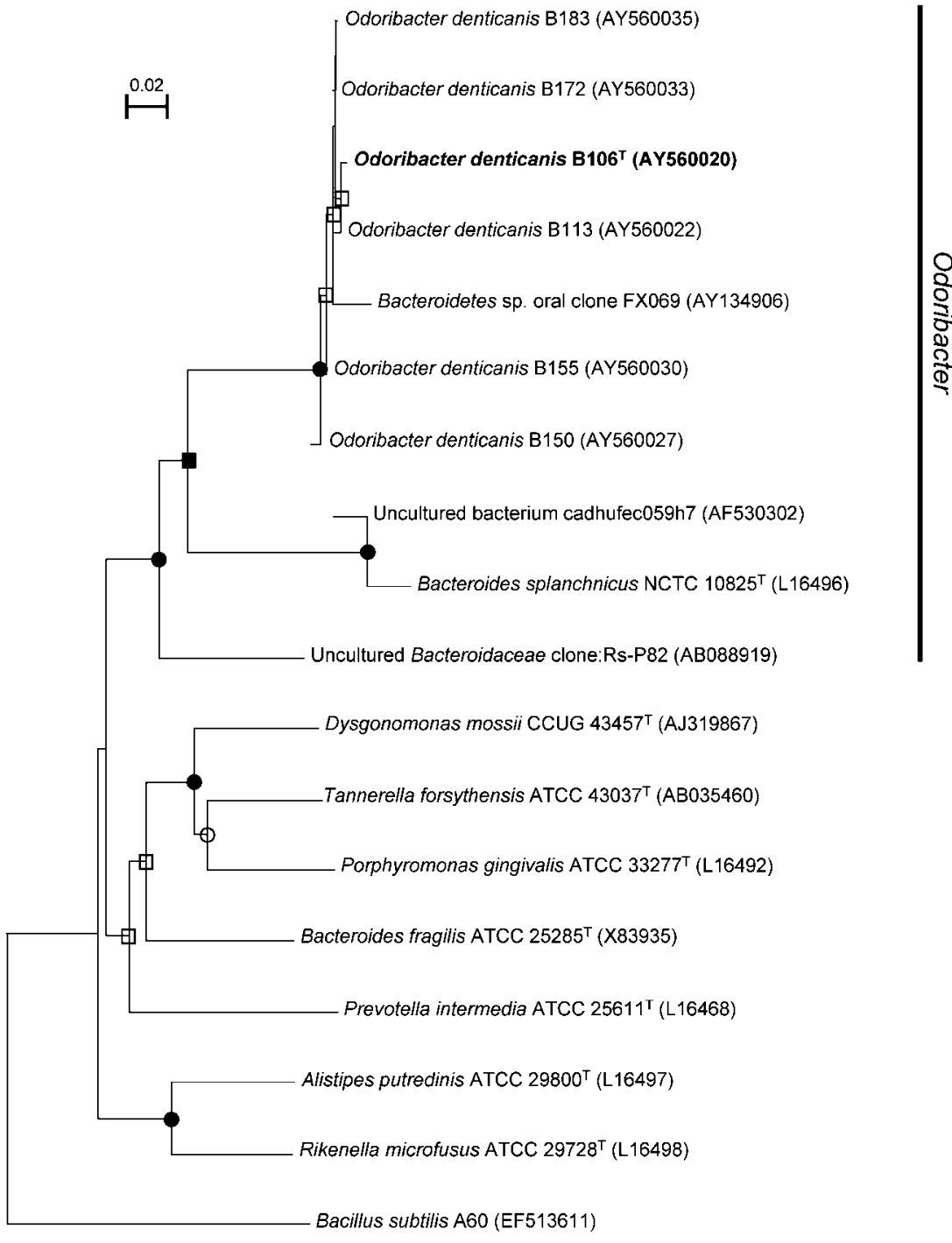

Fig. 1. Neighbour-joining phylogenetic tree for clinical isolates of $O$. denticanis gen. nov., $\mathrm{sp}$. nov. and representatives of the phylum Bacteroidetes. The tree was generated using CLUSTAL_X version 1.81 and NJ Plot software programs (both available from $\mathrm{ftp}: / / \mathrm{ftp}-$ igbmc.u-strasbg.fr/pub/ClustalX/). The tree was rooted to the Bacillus subtilis A60 16S rRNA gene sequence. Bootstrap analysis was performed using 1000 replicates. Bootstrap values are presented graphically $(\bullet,>950$; 口, >850; $\bigcirc,>700 ; \square,>500$; no designation, <500). Bar, 0.02 substitutions per nucleotide position.

relationships of the various FimA protein sequences. A very strong relationship existed (bootstrap value of $100 \%$ ) between the protein of strain $\mathrm{B} 106^{\mathrm{T}}$ and several of the type I fimbrillin proteins of Porphyromonas species.

The FimA data support the relationship between the $B$. splanchnicus/O. denticanis $\mathrm{B} 106^{\mathrm{T}}$ group and the genus Porphyromonas. Based on the $16 \mathrm{~S}$ rRNA gene phylogenetic data (Fig. 1) and the FimA phylogenetic data (Fig. 2), we propose that the subgroup of bacteria containing $B$. splanchnicus should be reclassified in a new genus, Odoribacter gen. nov., in the family 'Porphyromonadaceae' (Fig. 1). Additionally, we propose that B. splanchnicus should be reclassified as Odoribacter splanchnicus comb. nov.

\section{Structural analysis}

Strain $\mathrm{B}_{106^{\mathrm{T}}}$ and Porphyromonas gulae B 243 (Hardham et al., 2003, 2005a) were subjected to scanning electron microscopy to determine the cellular morphology. Briefly, 36-h liquid cultures in modified phytone/yeast/glucose medium (Hardham et al., 2003) were centrifuged at $1800 \mathrm{~g}$. The medium was replaced with $3 \%$ electron microscopygrade glutaraldehyde (Polysciences) in a $0.1 \mathrm{M}$ phosphate buffer $(\mathrm{pH} 7.3)$ and incubated at $4{ }^{\circ} \mathrm{C}$ for $1 \mathrm{~h}$. The cells were then washed twice in $0.1 \mathrm{M}$ phosphate buffer $(\mathrm{pH}$ 7.3) and suspended in buffered $1 \%$ osmium tetroxide (Polysciences) for $1 \mathrm{~h}$ at room temperature. The samples were dehydrated in a graded ethanol series with final dehydration done by immersion in hexamethyldisilazane for $15 \mathrm{~min}$, followed by air-drying for $1 \mathrm{~h}$. Samples were mounted on aluminium stubs and coated with $200 \AA$ gold in a Polaron SEM autocoating unit (Polaron Instruments). Each sample was examined by using a DS-130 scanning electron microscope (ISI). Images were captured using a Noran 4485 digital beam control interface (Noran Instruments). Fig. 3 shows scanning electron micrographs of Porphyromonas gulae B 243 and strain $\mathrm{B}_{106}{ }^{\mathrm{T}}$. The short rod-shaped morphology (mean length of $1.25 \mu \mathrm{m}$ ) of 


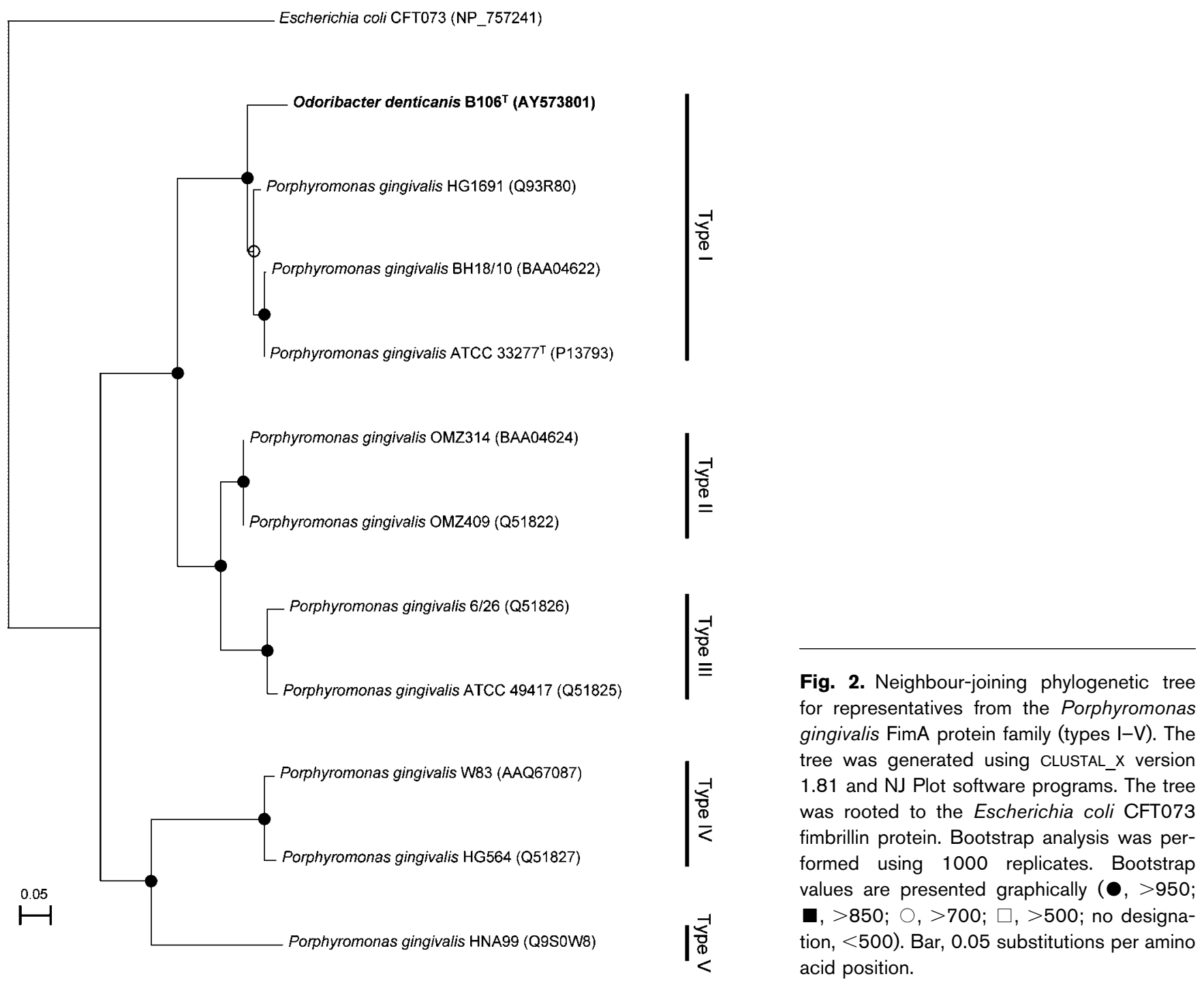

Porphyromonas gulae B 243 (Fig. 3a) is typical of members of the genus Porphyromonas. In contrast, strain $\mathrm{B}_{106^{\mathrm{T}}}$ appeared fusiform with tapered ends, with a mean cell length of $5.9 \mu \mathrm{m}$ (Fig. 3b). The morphology of strain B106 ${ }^{\mathrm{T}}$ is analogous to that of $T$. forsythensis under the same growth conditions (Tanner et al., 1986). The morphological difference between Porphyromonas gulae B 243 and strain $\mathrm{B} 106^{\mathrm{T}}$ further supports the placement of strain $\mathrm{B} 106^{\mathrm{T}}$ outside of the genus Porphyromonas.

\section{Mouse model of periodontal disease}

Several members of the genera Bacteroides, Porphyromonas and Prevotella are implicated as periodontal pathogens (Shah et al., 1998). As the O. denticanis isolates described herein were isolated from the crevicular space of dogs with periodontal disease, we sought to determine whether these isolates could cause disease in an experimental model of periodontal disease. We tested the isolates in an oral mouse model of periodontal disease (Baker et al., 1994). In this model, mice that had been pre-treated with antibiotics to reduce their oral flora were orally challenged with the bacteria in question. After a 42-day infection period, the maxillary buccal surfaces of each mouse were scored for alveolar bone loss. The distance from the cemento-enamel junction $(\mathrm{CEJ})$ to the alveolar bone crest $(\mathrm{ABC})$ is indicative of the amount of bone loss.

Fig. 4 shows the results of alveolar bone height measurements. The negative control animals (sham infected) were used to determine the base-line CEJ-ABC distance. Porphyromonas gingivalis ATCC 53977 was used as a positive control. The alveolar bone loss observed following Porphyromonas gingivalis ATCC 53977 infection was consistent with previously published results for this isolate (Baker et al., 2000; Evans et al., 1992a, b). Strain B106 ${ }^{\mathrm{T}}$ was capable of eliciting alveolar bone loss as shown by the increased CEJ-ABC distances in infected animals. The bone loss elicited by strain $\mathrm{B} 106^{\mathrm{T}}$ was equal to or greater than that generated by infection with Porphyromonas gingivalis 

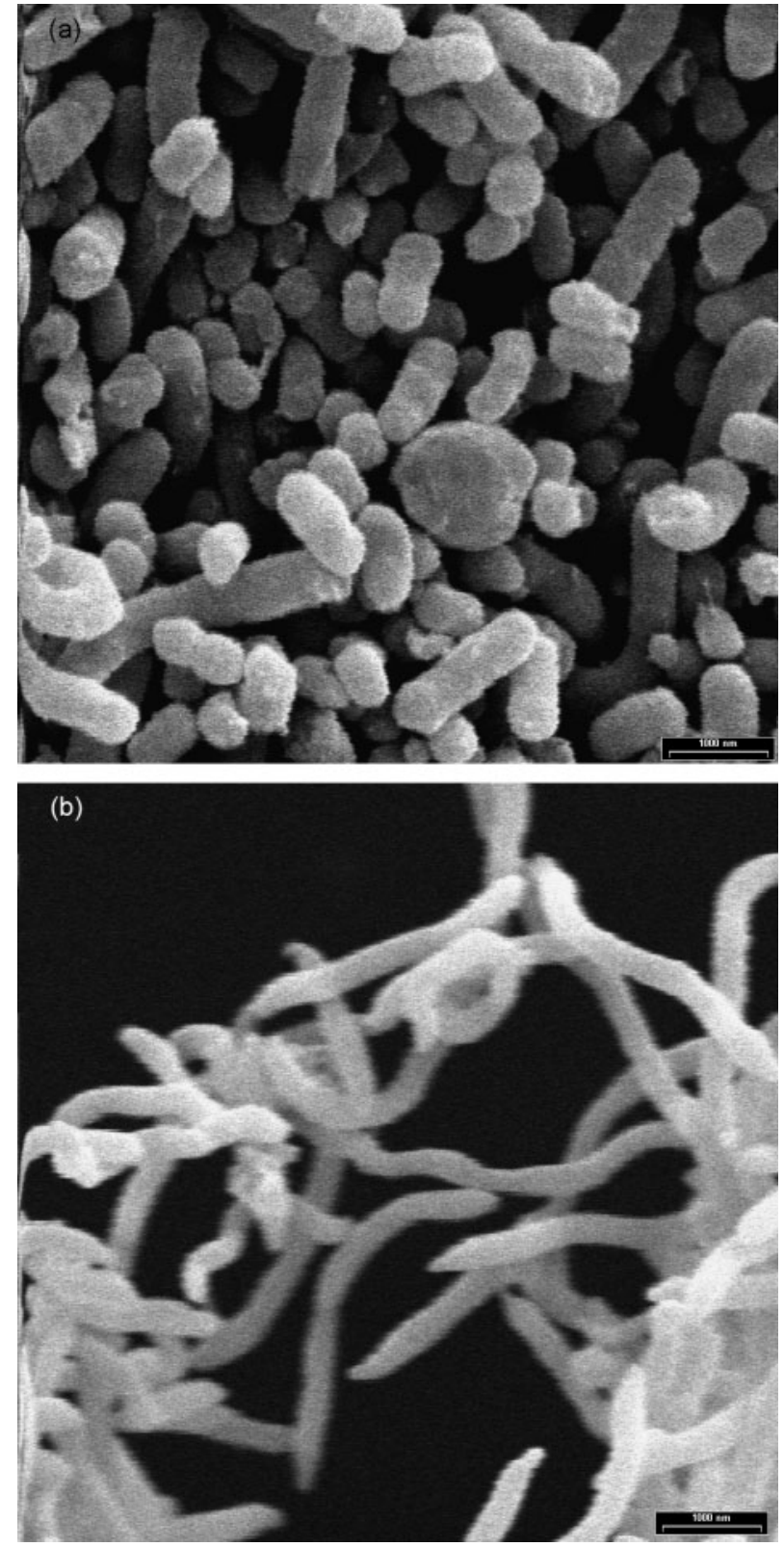

Fig. 3. Scanning electron micrographs of cells of Porphyromonas gulae B 243 (a) and strain B106 ${ }^{\top}$ (b). Bars, $1000 \mathrm{~nm}$.

ATCC 53977. It can be concluded that strain $B 106^{\mathrm{T}}$ is capable of inducing periodontitis in infected animals.

O. denticanis may prove to be an important periodontal pathogen in companion animals. Previous work by our group (Hardham et al., 2003, 2005a, b) and others (Fournier et al., 2001) has indicated that the periodontal pathogens in companion animals may be slightly different from those of humans. For example, Porphyromonas gulae has been identified in companion animals (Fournier et al., 2001; Hardham et al., 2003, 2005a), but not in humans. Since vaccines for periodontitis in humans (Page, 2000) and companion animals (Hardham et al., 2003, 2005b)

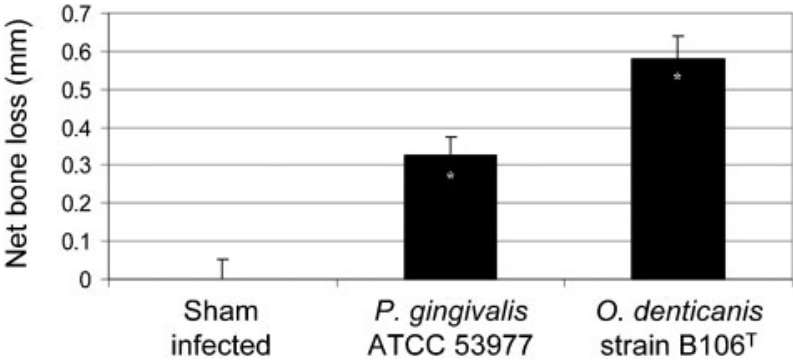

Fig. 4. Pathogenicity testing of strain $B 106^{\top}$ in the oral mouse model of periodontal disease. Sixteen mice were used for each test group. Mice were treated as described previously (Baker et al., 1994). Forty-two days post challenge, the mice were euthanized and the jaws were defleshed and stained. Fourteen independent measurements of the CEJ-ABC distance were taken along the buccal surface of the maxilla on each jaw. The net bone loss plus SE for each group is shown. *Statistically different from the negative control group $(P<0.05)$.

would aid in periodontal disease prevention programmes, $O$. denticanis should be considered as an important constituent in such vaccines.

We have presented data that demonstrate that a bacterium isolated from the periodontal pockets of dogs represents a previously unidentified species. Furthermore, we propose that the subgroup of bacteria in the genus Bacteroides containing B. splanchnicus should be reclassified as belonging to the family 'Porphyromonadaceae' in the genus Odoribacter gen. nov. We also propose that B. splanchnicus should be reclassified as Odoribacter splanchnicus comb. nov. and that the novel group of clinical isolates described herein should be classified as representing Odoribacter denticanis sp. nov.

All procedures in this study were approved by the Institutional Animal Care and Use Committee and were conducted in compliance with the Guide for Care and Use of Laboratory Animals, as well as with all internal company policies and guidelines.

\section{Description of Odoribacter gen. nov.}

Odoribacter [O.do.ri.bac'ter. L. n. odor smell; N.L. masc. n. bacter rod; N.L. masc. n. Odoribacter rod of (bad) smell].

Cells are anaerobic, Gram-negative, non-spore-forming, non-motile, fusiform in shape and catalase-positive. Colonies demonstrate pigmentation after $>7$ days of anaerobic growth at $37{ }^{\circ} \mathrm{C}$ on medium containing blood. The type species is Odoribacter splanchnicus.

\section{Description of Odoribacter splanchnicus comb. nov.}

Basonym: Bacteroides splanchnicus Werner et al. 1975 (Approved Lists).

The description is that given by Werner et al. (1975). 
The type strain is ATCC $29572^{\mathrm{T}}\left(=\right.$ CCUG $21054^{\mathrm{T}}=$ CIP $104287^{\mathrm{T}}=$ DSM $20712^{\mathrm{T}}=$ LMG $8202^{\mathrm{T}}=$ NCTC $\left.10825^{\mathrm{T}}\right)$.

\section{Description of Odoribacter denticanis sp. nov.}

Odoribacter denticanis (den.ti.ca' nis. L. n. dens -tis tooth; L. gen. n. canis of a dog; N.L. gen. n. denticanis of the tooth of a dog).

Exhibits the following properties in addition to those given in the genus description. Colonies are punctiform and begin to show pigmentation (tan-black) after 10-12 days of incubation at $37{ }^{\circ} \mathrm{C}$ in an anaerobic environment on medium containing blood. Colonies are haemolytic on Brucella blood agar, and are resistant to kanamycin, vancomycin and colistin (antibiotic discs from Anaerobe Systems). Colonies on egg yolk agar (Anaerobe Systems) have neither lecithinase nor lipase activities. There is no evidence of bacterial swarming since distinct colonies appear on numerous media types.

The type strain is strain $\mathrm{B} 106^{\mathrm{T}}$ (=ATCC PTA-

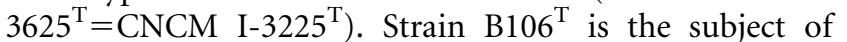
the US patent application US20030228328 and the worldwide patent application WO2003054755. The strain is now available to the public.

\section{Acknowledgements}

The authors are grateful to Bruce Paster, David Lowery and Raja Krishnan for their insight, suggestions and critical review of this manuscript.

\section{References}

Altschul, S. F., Gish, W., Miller, W., Myers, E. W. \& Lipman, D. J. (1990). Basic local alignment search tool. J Mol Biol 215, 403-410.

Baker, P. J., Evans, R. T. \& Roopenian, D. C. (1994). Oral infection with Porphyromonas gingivalis and induced alveolar bone loss in immunocompetent and severe combined immunodeficient mice. Arch Oral Biol 39, 1035-1040.

Baker, P. J., Dixon, M., Evans, R. T. \& Roopenian, D. C. (2000). Heterogeneity of Porphyromonas gingivalis strains in the induction of alveolar bone loss in mice. Oral Microbiol Immunol 15, 27-32.

Eckburg, P. B., Bik, E. M., Bernstein, C. N., Purdom, E., Dethlefsen, L., Sargent, M., Gill, S. R., Nelson, K. E. \& Relman, D. A. (2005). Diversity of the human intestinal microbial flora. Science 308, 1635-1638.

Evans, R. T., Klausen, B. \& Genco, R. J. (1992a). Immunization with fimbrial protein and peptide protects against Porphyromonas gingivalis-induced periodontal tissue destruction. Adv Exp Med Biol 327, 255-262.

Evans, R. T., Klausen, B., Sojar, H. T., Bedi, G. S., Sfintescu, C., Ramamurthy, N. S., Golub, L. M. \& Genco, R. J. (1992b). Immunization with Porphyromonas (Bacteroides) gingivalis fimbriae protects against periodontal destruction. Infect Immun 60, 2926-2935.

Fournier, D., Mouton, C., Lapierre, P., Kato, T., Okuda, K. \& Menard, C. (2001). Porphyromonas gulae sp. nov., an anaerobic, Gram-negative coccobacillus from the gingival sulcus of various animal hosts. Int J Syst Evol Microbiol 51, 1179-1189.

Haffajee, A. D. \& Socransky, S. S. (1994). Microbial etiological agents of destructive periodontal diseases. Periodontol 2000 5, 78-111.

Hardham J. M., King, K. W., Krishnan, R., Dreier, K. J., \& McGavin, D. R. (2003). Vaccine for periodontal disease. WO 2003/054755 A2.

Hardham, J., Dreier, K., Wong, J., Sfintescu, C. \& Evans, R. T. (2005a). Pigmented-anaerobic bacteria associated with canine periodontitis. Vet Microbiol 106, 119-128.

Hardham, J. M., Reed, M., Wong, J., King, K., Laurinat, B., Sfintescu, C. \& Evans, R. T. (2005b). Evaluation of a monovalent companion animal periodontal disease vaccine in an experimental mouse periodontitis model. Vaccine 23, 3148-3156.

Harvey, C. E. (1998). Periodontal disease in dogs. Etiopathogenesis, prevalence, and significance. Vet Clin North Am Small Anim Pract 28, 1111-1128.

Holt, J. G., Krieg, N. R., Sneath, P. H. A., Staley, J. T. \& Williams, S. T. (editors) (1994). Bergey's Manual of Determinative Bacteriology, 9th edn. Philadelphia: Lippincott, Williams \& Wilkins.

Page, R. C. (2000). Vaccination and periodontitis: myth or reality. $J$ Int Acad Periodontol 2, 31-43.

Paster, B. J., Dewhirst, F. E., Olsen, I. \& Fraser, G. J. (1994). Phylogeny of Bacteroides, Prevotella, and Porphyromonas spp. and related bacteria. J Bacteriol 176, 725-732.

Rumpf, R. W., Griffen, A. L., Wen, B. G. \& Leys, E. J. (1999). Sequencing of the ribosomal intergenic spacer region for strain identification of Porphyromonas gingivalis. J Clin Microbiol 37, 2723-2725.

Saitou, N. \& Nei, M. (1987). The neighbor-joining method: a new method for reconstructing phylogenetic trees. Mol Biol Evol 4, 406-425.

Sakamoto, M., Suzuki, M., Umeda, M., Ishikawa, I. \& Benno, Y. (2002). Reclassification of Bacteroides forsythus (Tanner et al. 1986) as Tannerella forsythensis corrig., gen. nov., comb. nov. Int J Syst Evol Microbiol 52, 841-849.

Shah, H. N. \& Collins, M. D. (1988). Proposal for reclassification of Bacteroides asaccharolyticus, Bacteroides gingivalis, and Bacteroides endodontalis in a new genus, Porphyromonas. Int J Syst Bacteriol 38, 128-131.

Shah, H. N., Gharbia, S. E. \& Duerden, B. I. (1998). Bacteroides, Prevotella, and Porphyromonas. In Microbiology and Microbial Infections, pp. 1305-1330. Edited by A. Balows \& B. I. Duerden. London: Oxford University Press.

Slots, J., Ashimoto, A., Flynn, M. J., Li, G. \& Chen, C. (1995). Detection of putative periodontal pathogens in subgingival specimens by $16 \mathrm{~S}$ ribosomal DNA amplification with the polymerase chain reaction. Clin Infect Dis 20 (Suppl. 2), S304-S307.

Tanner, A. C. R., Listgarten, M. A., Ebersole, J. L. \& Strzempko, M. N. (1986). Bacteroides forsythus sp. nov., a slow-growing, fusiform Bacteroides sp. from the human oral cavity. Int J Syst Bacteriol 36, 213-221.

Thompson, J. D., Gibson, T. J., Plewniak, F., Jeanmougin, F. \& Higgins, D. G. (1997). The CLUSTAL_X windows interface: flexible strategies for multiple sequence alignment aided by quality analysis tools. Nucleic Acids Res 25, 4876-4882.

Werner, H., Rintelen, G. \& Kunstek-Santos, H. (1975). A new butyric acid-producing Bacteroides species: B. splanchnicus n. sp. Zentralbl Bakteriol [Orig A] 231, 133-144 (in German). 